\title{
A Practical Approach to Establishing a Practice- Based Research Network Stakeholder Engagement Infrastructure
}

\author{
Anne H. Gaglioti, MD, MS, FAAFP, Denita Walston, MS, \\ Cirila Estela Vasquez Guzman, PhD, Nikita Toppin Dera, MPH, Clarissa Ortiz, MS, \\ LaShun C. Wright, MSA, Tisa Roberts, MD, Sharon Parker, RN, and Vicki Young, PhD
}

Introduction: While there have been several articles detailing the importance of stakeholder engagement in research broadly and in practice-based research networks (PBRNs) specifically, few of these articles offer a replicable engagement approach that is detailed enough to translate to another setting. The goal of this article is to offer a detailed example of building stakeholder engagement infrastructure that could be replicated or translated to other settings.

Approach: We offer a review of 1 regional PBRN's approach to building a stakeholder engagement infrastructure over a 2 -year period by describing engagement activities deployed across a large, regional PBRN including a needs assessment around research and training conducted in each state of the network and a centralized conference where themes from that needs assessment were leveraged to produce a stakeholder-defined research agenda and elect a steering committee.

Results: Products from this process include the stakeholder-defined research agenda as well as a multi-level organizational framework for assessing facilitators and barriers in a large PBRN and an example of a framework of individualized stakeholder group preferences for engagement modalities.

Conclusions: This article presents a detailed timeline and replicable approach to building a stakeholder engagement infrastructure in a regional PBRN. This article details a practical process that is embedded in the lived values of practice-based research. ( $\mathrm{J}$ Am Board Fam Med 2019;32: 695-704.)

Keywords: Needs Assessment, Organizations, Practice-Based Research

The Agency for Health care Research and Quality describes practice-based research networks (PBRNs) as involving "practicing clinicians in asking and answering clinical and organizational questions central to

This article was externally peer reviewed.

Submitted 1 February 2019; revised 14 June 2019; accepted 18 June 2019.

From the National Center for Primary Care, Morehouse School of Medicine, Atlanta, GA (AHG, DW, NTD); Department of Family Medicine, Morehouse School of Medicine, Atlanta, GA (AHG); Department of Sociology, University of New Mexico, Albuquerque, NM (CEVG); Florida Association of Community Health Centers, Talahassee, FL (CO); Georgia Primary Care Association, Decatur, GA (LCW); Opportunities Industrialization Center, Rocky Mount, NC (TR); Alabama Primary Health Care Association, Montgomery, AL (SP); South Carolina Primary Health Care Association, Columbia, SC (VY).

Funding: This work was funded through a Patient-Centered Outcomes Research Institute (PCORI) Eugene Washington PCORI Engagement Award (EAIN-3315). primary health care." However, there are few practical descriptions of how PBRNs approach engaging clinicians and other stakeholder groups in their research processes. There are descriptions of how stakeholders have been engaged in specific projects $^{2}$ or aspects of a research process, like identifying research questions. ${ }^{3}$ In addition, Dolor et $\mathrm{al}^{4}$ make recommendations to incorporate stakeholder needs into strategic goals and to "develop an organizational structure" that includes creating "venues" for stakeholders to share ideas for projects in their comprehensive guide to PBRN research good practices. Both Green ${ }^{5}$ and the PBRN Good Practices

Conflict of interest: none declared.

Corresponding author: Anne Gaglioti, MD, MS, FAAFP, National Center for Primary Care, 720 Westview Drive, SW, Atlanta, GA 30310 (E-mail: agaglioti@msm.edu). 
Guide describe common elements of $\mathrm{PBRN}^{4}$, but do not address how stakeholder views should be incorporated outside of identifying the need for 2-way communication mechanisms, prioritization, and creation of venues for stakeholder engagement, and establishment of leadership structure that incorporated stakeholders. Despite these excellent charges, there are no practical blueprints we know of to build infrastructure for a successful engagement infrastructure to function. For example, Dolor et $\mathrm{al}^{4}$ offer recommendations to "build organizational structure ... to ensure buy-in and participation," but do not offer specific approaches to build such infrastructure. One reason specific approaches are lacking may be because PBRN infrastructure itself is highly variable. $^{6}$

Concepts of stakeholder engagement in research have evolved over the last decade. The comparative effectiveness research movement has outlined a framework for effective stakeholder engagement ${ }^{7}$ and the Patient Centered Outcomes Research Institute (PCORI) has prioritized engagement of patient stakeholders and other stakeholder groups who have not been engaged in traditional academic research spaces ${ }^{8}$; PCORI has also uniquely pioneered the evaluation of the impact of its engagement priorities on research process outcomes. ${ }^{9}$

The goal of this article is to offer 1 example of a replicable approach for building and using a stakeholder engagement infrastructure in a PBRN. This approach operationalizes the recommendations of Dolor et $\mathrm{al}^{4}$ and Green ${ }^{5}$ to establish 2-way communication with stakeholders and to build organizational infrastructure that allows stakeholders to meaningfully engage in research. We also incorporated principles from the Community-Based Participatory Research Model around trust-building ${ }^{10}$ and partnership ${ }^{11}$ and the Community-Oriented Primary Care Model as a mechanism to engage needs of community members. ${ }^{12}$ Our approach aimed to integrate stakeholders as partners in research in a geographically large PBRN of Federally Qualified Health Centers (FQHCs). The process had 2 main components: 1) a stakeholder needs assessment around research and training priorities and relationship building, and 2) establish a stakeholder-defined research agenda and elect stakeholder network leaders. This approach can be tailored to other settings and used as a guide to establish infrastructure to engage stakeholder communities as partners in research.

\section{One Network Example: The Southeast Regional Clinicians Network History and Need for Renewed Engagement Infrastructure}

In 1995, Southeast Regional Clinicians Network (SERCN) was designated as a PBRN of FQHCs and Primary Care Associations (PCAs) in 8 southeastern states and is administered from the $\mathrm{Na}$ tional Center for Primary Care (NCPC) at Morehouse School of Medicine in Atlanta, Georgia. FQHCs compose the primary care safety net and provide comprehensive primary care, dental, and mental health services to a disproportionately poor, minority, and medically underserved population. Every state has a PCA, which is a leadership and advocacy organization for the state's FQHCs that serves as a resource for training and technical assistance. SERCN encompasses the 8 states that make up the Department of Health and Human Services Region IV (Alabama, Mississippi, North Carolina, South Carolina, Florida, Georgia, Kentucky, and Tennessee). These states are home to 203 FQHCs with over 1700 clinic sites serving over 4 million patients.

SERCN was an active PBRN until 2011, after the departure of the network director. However, the NCPC maintained relationships with key stakeholders and successfully engaged all states in a large funding proposal in 2015. The NCPC recruited a new network director in late 2015 who was charged to revitalize the network. This was no simple task given the infrastructure challenges of the preceding years, the network's broad geographic catchment area, and limited funding support and personnel. Despite these challenges, the director and network coordinator engaged leaders of all the state PCAs in the network to assess their broad needs and explore opportunities for projects from late 2015 through early 2016.

\section{Securing Funding to Build Stakebolder Engagement Infrastructure}

This initial stakeholder engagement process led the team to conclude that funding would be needed to effectively rebuild the network's stakeholder engagement infrastructure. This decision was driven by the significant time needed, the large geographic 
Figure 1. Overview of SERCN PBRN engagement infrastructure building project timeline, activities, and products SERCN, southeast regional clinicians network; PBRN, practice-based research networks.

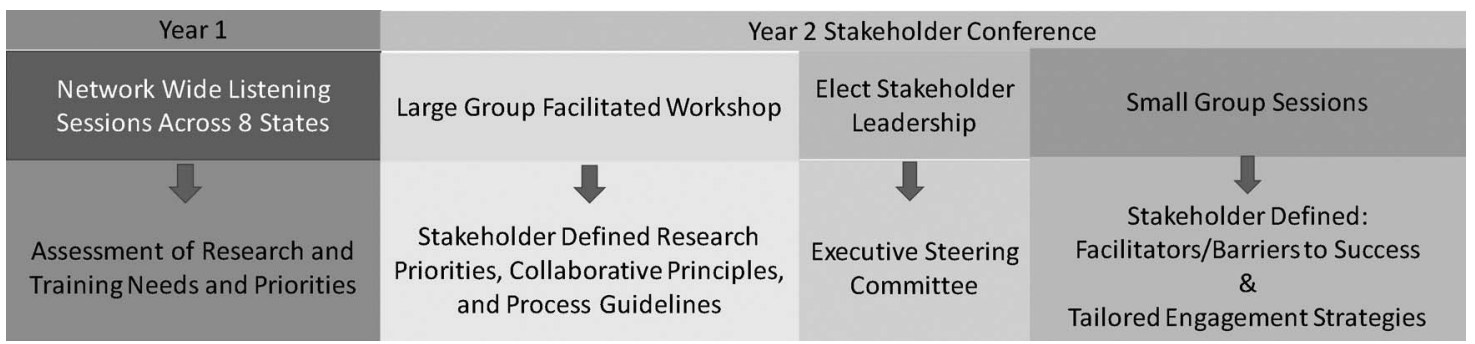

footprint of the network, and the realization that harmonizing regional versus state specific needs and values around research would require a structured approach. The team applied for a PCORI Engagement Award in February of 2016 and their project titled, Engaging Stakeholders to Build Infrastructure for patient centered outcomes research (PCOR) in the Primary Care Safety Net, was funded from July 2016 through June 2018. The overall timeline and activities and products of the project are outlined in Figure 1.

\section{Identifying and Engaging Stakeholders Around Research and Training Priorities Network-Wide Listening and Engagement Sessions}

To engage a broad group of stakeholders, SERCN worked with PCAs to identify state-wide PCA events attended by geographically diverse FQHC stakeholders. Listening sessions were scheduled at these events with the help of key PCA leaders. A relationship-building phase with PCA leaders led up to coordinating the listening session. We worked with PCA meeting organizers to identify and recruit English speaking FQHC and PCA stakeholders who had interest or experience as leaders, clinicians, or quality/research personnel. Some barriers to recruitment included the time constraints and competing demands of PCA personnel. We addressed these through persistent communication, relationship building, and reciprocal support of the conference as a speaker or exhibitor. Participants were recruited via email and/or phone before the scheduled meeting by PCA partners using the conference registration list. During the sessions, attendees were detailed on the mission and goals of SERCN and the focus group objectives. These sessions built the foundation of the SERCN communication platform and leadership pipeline; attendees signed up for SERCN communi- cations and self-identified if they were interested in a SERCN leadership position. Most importantly, these sessions allowed the SERCN team to understand key health issues and research, quality, and operational priorities of network stakeholders.

Eight sessions (1 per state) were conducted from August 2016 to May 2017. There were a total 74 participants and groups ranged in size from 3 to 13 stakeholders. Stakeholders included clinicians, nurses, health information technology experts, quality improvement staff, FQHC leaders, PCA leaders, and community organization leaders. Participants were compensated with a $\$ 50$ gift card for their participation and refreshments were provided. Listening sessions lasted approximately 90 minutes. Each session was recorded and transcribed verbatim. The session was structured using a guide but use of the guide was flexible based on dynamics of each group (Table 1). The same facilitator, the network director, who had training in qualitative and PBRN research methods, conducted all the focus groups.

\section{Qualitative Analysis of Stakeholder Research and Training Needs Assessment}

The SERCN research team included 1 clinician researcher who conducted all the listening sessions and 2 qualitative research assistants, 1 with a doctorate in sociology and 1 with master's level training. The team identified emergent themes from the focus group transcripts and notes using an immersion crystallization approach. ${ }^{13}$

\section{Leveraging Engagement Infrastructure to Establish a Stakeholder-Defined Research Agenda Convening Network Stakebolders}

In year 2 , we identified 1 or 2 key stakeholders in each state who participated in the listening ses- 
Part 1: Quality Improvement and Research Assessment

1. What are the most important health and health care delivery issues that face providers, health systems, community members, and local organizations in your service area

2. What efforts/projects are underway currently to work on improving outcomes in these areas?

3. What types of projects or efforts do you wish were underway in your community? What types of projects are priorities for the future for your primary care association or center?

4. How might SERCN best help with the implementation, dissemination, or funding of projects underway in your state?

5. How are patient values and community values currently incorporated in to designing ways to look at and solve issues around health and health care delivery in your community/practice site/organization?

6. Are there important stakeholders in your service areas who do not currently have a voice in efforts to improve health or health care delivery? How could this be different or more inclusive?

7. What is the biggest barrier you face to participating in quality improvement or patient centered research? What might be done to break down these barriers?

Part 2: Educational and Reciprocal Needs

1. What are some key educational and continuing education needs of your organization or members that SERCN might meet?

2. What would be the best venue to meet those needs?

3. What other services could SERCN offer that would help build a reciprocal relationship between our organizations? (inclusion on projects, continuing education, conferences, technical support) What would that look like?

SERCN, southeast regional clinicians network.

sions and/or self identified as interested in a SERCN leadership position to attend a networkwide stakeholder meeting in Atlanta. The regional stakeholder engagement conference was held on February 19, 2018 at Morehouse School of Medicine. SERCN reimbursed attendees for travel expenses. The objectives of this meeting were: 1) to engage SERCN stakeholders around practice-based research in the primary care safety net; 2) to define a SERCN research agenda; 3) to establish a SERCN steering committee; and 4) to learn how SERCN could improve stakeholder engagement efforts. Stakeholders convened at the regional conference were thought leaders in their organizations and included clinical quality leaders, medical directors, and member and patient engagement specialists at PCAs and FQHCs. These state champion stakeholders were convened for several reasons: 1) SERCN relies on PCA partners to identify FQHC needs and act as an intermediary for project proposal and implementation phases, 2) they understood the high-level needs of the region and could identify common ground for the direction of our regional network, and 3) they held influential positions and were well suited to translate the network research agenda into action. Thirteen stakeholders attended, representing all states in the network. This was largely a working meeting, although we invited outside speakers on topics of identified interest to the group. See Appendix for the full conference agenda.

\section{Translation of Needs Assessment Findings to Actionable Research Agenda}

The network director led a workshop to guide the stakeholder group through a process of crafting a needs-based research agenda that incorporated key health issues in the region, operational/quality priorities of SERCN members, existing quality improvement infrastructure, and future goals/needs around research and training drawn from the regional listening sessions. The workshop lasted 2 hours and began with a review of the qualitative data collected from year 1 of the project using a PowerPoint presentation format.

The network director then asked stakeholders to translate, condense, and prioritize the themes of the listening sessions into a research agenda for the network. Some of the guiding questions used to facilitate this discussion included: 1) What are the high-level values that we will uphold in our work together? 2) What priority areas and populations were consistently identified across the region as areas of need and interest? 3) How should we work with network stakeholders? The network director facilitated the discussion using active-listening techniques, checked for understanding, and asked probing and clarifying questions. The network director took notes and edited the documents on a PowerPoint slide projected on a screen 


\begin{tabular}{|c|c|}
\hline $\begin{array}{l}\text { 1. Support health center infrastructure, sustainability, and mission } \\
\text { to improve health outcomes. }\end{array}$ & $\begin{array}{l}\text { Staff wellbeing and retention } \\
\text { Workforce development } \\
\text { Strive for unified standard of care }\end{array}$ \\
\hline $\begin{array}{l}\text { 2. Measure the FQHC impact on broad economic, health, and } \\
\text { utilization outcomes. }\end{array}$ & $\begin{array}{l}\text { Test meaningful outcome measures } \\
\text { Whole person outcomes } \\
\text { Leverage socioeconomic strengths of FQHCs } \\
\text { Explore return on investment of FQHCs }\end{array}$ \\
\hline 3. Prioritize work that is meaningful to patients and communities. & $\begin{array}{l}\text { Focus on system navigation and care transitions } \\
\text { Link with community organizations } \\
\text { Prioritize projects that address care of the whole person }\end{array}$ \\
\hline 4. Support streamlining data infrastructure in FQHCs. & $\begin{array}{l}\text { Align research with existing quality measures } \\
\text { Support autonomy of FQHCs to drive unified quality } \\
\text { measures across payors } \\
\text { SERCN should be aware of current quality and data } \\
\text { priorities in the network }\end{array}$ \\
\hline $\begin{array}{l}\text { 5. Mental and behavioral health integration in the primary care } \\
\text { safety net setting. }\end{array}$ & $\begin{array}{l}\text { Specific focus on substance use disorder treatment and } \\
\text { prevention }\end{array}$ \\
\hline $\begin{array}{l}\text { 6. Study and test care delivery models for medically and socially } \\
\text { complex populations. }\end{array}$ & $\begin{array}{l}\text { Chronic disease management } \\
\text { Self-management and adherence } \\
\text { Standardized care to promote equity } \\
\text { Translate lessons from practice to support evidence }\end{array}$ \\
\hline
\end{tabular}

FQHC, federally qualified health center; SERCN, southeast regional clinicians network.

and received real-time feedback on documentation from the group. Group consensus was reached around what to include in each of the final research agenda components. The documents were presented as living documents that would be updated as the needs of network stakeholders evolved. The group divided the research agenda into 3 parts: 1 ) Key Priority Areas and Populations (Table 2), 2) Collaborative Principles, and 3) Research Procedures (Table 3).

The priority areas defined by SERCN stakeholders reflected the medical and social complexity of patients seen in FQHCs and traditional values of PBRNs. ${ }^{14,15}$ Priority areas included implementing models that bolstered FQHC infrastructure through workforce stability and wellness; measuring the economic and health impact that FQHCs have on their communities; development and testing models of care for medically and socially complex patients health information technology; and behavioral health and substance use disorder integration into primary care.

SERCN stakeholders formulated overarching guidelines for collaboration and made specific recommendations to integrate stakeholder wisdom across the spectrum of research processes, from project identification to dissemination. Notable collaborative guidelines included cultivation of an environment of trust and transparency, the importance of crediting stakeholders for their contributions, a commitment to regular 2-way communication in person and via conference call, and the role of the network to serve as a clearinghouse for scalable ideas/models of care. Stakeholders were specific about how SERCN should involve stakeholders at each stage of the research process and valued stakeholder input on project identification, the testing and implementing of sustainable care models, minimizing recruitment and data reporting efforts through technical support, shared interpretation of results, and dissemination strategies that use traditional and nontraditional platforms. In addition, stakeholders identified that the work produced by the network be used as an engagement tool for a broader group of health center stakeholders.

\section{Election of Executive Steering Committee}

Nomination forms were distributed to all attendees for a position on the 3-person Steering Committee. The responsibilities of the Steering Committee members were described before the nomination process and included: 1) provide guidance on the strategic direction of the network, project selection, and results dissemination; 2) attend quarterly conference calls; 3 ) attend yearly in person meetings; 3 ) 
Table 3. SERCN Stakeholder-Defined Research Agenda: Research Processes and Collaborative Principles

SERCN Guiding Principles for Research Processes

Project identification

Vet ideas with stakeholders

Project design and implementation

Encourage ideas from all levels of the network

Recruitment

Focus on streamlining processes instead of adding to workflow

Prioritize sustainability

Data collection

Practice facilitation is needed to help with recruitment

Minimize data collection burden for the health center

Results reporting

Data should be meaningful across stakeholders

Should be transparent and inclusive

Prioritize dissemination to participants

Package results to be interpretable to broad audiences

Results interpretation

Interpret in the spirit of transparency and inclusiveness

Goal to send for review to a broad group of stakeholders

Dissemination

Potential outlets include regional meetings, local journals, webinars for clinicians, primary care association newsletters

Dissemination should be shared and claimed by as broad a group of stakeholders as possible

Leverage work as a tool to recruit broader participation in the network

SERCN Collaborative Principles for Working Together

Learn from each other and magnify successes across the region

Credit and recognize people for the work they do

Be mutually committed to collaboration

Create an environment of trust and transparency

Build a clearinghouse of best practices and scalable models

Have regular communication including a yearly in person meeting and quarterly conference call

Be informed and mindful of each other's time constraints and competing priorities

Employ a clover leaf style of communication. SERCN will trust primary care associations to select priorities and we will value bidirectional communication where the hub is not the most important or the originator of ideas.

FQHC, federally qualified health center; SERCN, southeast regional clinicians network.

commit to a 2-year term. All nominated individuals were included on ballots that were distributed and tallied. Steering Committee members were announced at the end of the meeting.

\section{Stakeholder Definition of Facilitators and Barriers to Conducting Research in the Network}

In a 1-hour workshop, stakeholders divided into small groups to identify barriers and facilitators to operationalizing the new SERCN research agenda. This facilitated discussion was organized into a multi-level framework to distinguish challenges and strengths across a broad variety of stakeholder groups and organizational levels. The most significant barriers to implementing research included limited time and human capital to implement projects and the most consistent facilitators to success included the human capital, relationships, and experience of past success across multiple levels of the organizational structure. A full list of the multi-level barriers and facilitators to the implementation of the research agenda are detailed in Table 4.

\section{Stakebolder Input on Engagement Approaches}

As a portion of the same small group workshop, stakeholders gave feedback on SERCN engagement approaches and how approaches might be adapted to better meet their needs in the future. This discussion was segmented to identifying differing engagement needs and preferences across network stakeholder groups. Stakeholder subgroups included advocacy and policy stakeholders, funders and academic partners, PCAs, FQHCs, and patients. Stakeholders recommended engaging national advocacy partners at the National Association for Community Health Centers, the Health Resources and Services Administration, and state PCA gov- 
Table 4. Multilevel Facilitators and Barriers to Implementing the SERCN Research Agenda

\begin{tabular}{|c|c|c|}
\hline Organizational Level & Barriers & Facilitators \\
\hline Research network & $\begin{array}{l}\text { Lack of data uniformity } \\
\text { Competing priorities and time } \\
\text { Need for effective communication platform } \\
\text { Challenges for IRB processes }\end{array}$ & $\begin{array}{l}\text { Robust knowledge base } \\
\text { Track record of successful collaboration } \\
\text { Good leadership } \\
\text { Credibility and resources }\end{array}$ \\
\hline PCA & $\begin{array}{l}\text { Can only serve as a connector between network } \\
\text { and FQHCs } \\
\text { If projects are not sustainable, then difficult to } \\
\text { recruit FQHCs }\end{array}$ & $\begin{array}{l}\text { Dedicated staff with experience and } \\
\text { commitment to the network } \\
\text { Strong history of collaboration regionally } \\
\text { Strong relationships with FQHCs } \\
\text { Successful at engaging consumers } \\
\text { Effective communication strategies } \\
\text { Strong policy and advocacy platform }\end{array}$ \\
\hline FQHC & $\begin{array}{l}\text { Limited staffing to support research } \\
\text { Data infrastructure is limited } \\
\text { Competing priorities } \\
\text { High turnover and burnout rate of staff/providers }\end{array}$ & $\begin{array}{l}\text { Strong public health infrastructure } \\
\text { Community based organizations } \\
\text { Strong ties to community } \\
\text { Population diversity }\end{array}$ \\
\hline Provider & $\begin{array}{l}\text { Change fatigue } \\
\text { Provider retention and turnover } \\
\text { Provider burnout } \\
\text { Providers are under resourced }\end{array}$ & $\begin{array}{l}\text { FQHC's leadership in the arena of quality of } \\
\text { care measurement, pay for performance } \\
\text { Data-rich environment } \\
\text { Electronic health record systems and } \\
\text { population management tools } \\
\text { Platform for direct patient engagement } \\
\text { FQHCs are advocates in the community } \\
\text { Existing integrated care models }\end{array}$ \\
\hline $\begin{array}{l}\text { Patient and community } \\
\text { level }\end{array}$ & $\begin{array}{l}\text { Mistrust/fear of research } \\
\text { Transportation needs } \\
\text { Need adequate compensation } \\
\text { Lack of time and resources to participate }\end{array}$ & $\begin{array}{l}\text { Diversity of services } \\
\text { Cultural diversity } \\
\text { Medical knowledge and front-line experience } \\
\text { can inform research questions and } \\
\text { interpretation }\end{array}$ \\
\hline
\end{tabular}

FQHC, federally qualified health center; IRB, institutional review board; PCA, primary care association; SERCN, southeast regional clinicians network.

ernment relations offices to explore opportunities for collaboration around policy, payor, quality measurement, and legislative issues impacting FQHCs regionally and nationally. Engagement strategies for academic partners and funders included presentations at research meetings and peer reviewed publications as well as cultivating relationships with funders around the potential for practice-based research in FQHCs to improve relevance of research to communities and translatability of research outcomes. PCA stakeholders preferred email, conference/phone calls, in person centralized conferences yearly, and in person outreach to PCA events as mechanisms of engagement. Stakeholders recommended that we receive feedback from and disseminate information to FQHC stakeholders through the PCAs in each state because PCAs had well-established relationships with FQHC staff and knowledge of the needs and strengths of health centers in their states. When engaging patients, stakeholders recommended leveraging FQHC and PCA relationship with community-based organizations, mailings, social media, and messaging through local media outlets as effective potential engagement strategies.

\section{Discussion and Potential Applications of this Approach}

SERCN measured the success of this approach through the engagement infrastructure yielded by this process and the products that were created from it. To date, this engagement infrastructure has yielded funding proposals (7 in 2018 to 19), active funded projects, (2) scholarly presentations, (4) routine engagement in quarterly stakeholder calls across the network, attendance at a second 
annual stakeholder conference in March of 2019 with representation from every state in our network, and engagement of policy leaders, funding organizations, and academic partners. This approach adds to the current literature on patient engagement by providing a case-study that serves as a practical template in a PBRN setting on which to implement best practices around stakeholder engagement that have been put forth in the literature. $^{4,9,12}$ This infrastructure allows the PBRN and key stakeholders to establish trust and relationships that in turn support the effectiveness of venues and mechanisms to integrate stakeholders as partners in research. This goes beyond the calls in the current PBRN literature to establish leadership and bidirectional communication platforms by outlining a process for stakeholders to act as research partners, defining the priorities and collaborative principles for the group in the PBRN setting. This approach blends and effectively operationalizes the community/stakeholder centrality of community-oriented primary care and community-based participatory research with the practical guidelines of the PBRN best practices. It is also novel because it provides a specific timeline to gauge what is realistic to expect when planning for development of an engagement infrastructure. This realistic timeline is often underestimated in project proposals and funders/researchers/and other stakeholders may have unrealistic expectations as to how quickly relationships can be built, fostered, and then operationalized into trust and new work.

One limitation of this engagement infrastructure building process is that it focused on health center and primary care association stakeholders and did not explicitly include patient stakeholders. Currently, SERCN is addressing this limitation by applying this approach to engage patients in our network via listening sessions, establishment of a patient advisory board, and delivery of a researchcapacity building curriculum to patient advisory board members. The result of this patient engagement infrastructure building project will be a revised research agenda, and standard processes developed by the patient advisory board incorporating patient stakeholder perspectives across SERCN's research processes, from project identification to results dissemination. Another limitation of this approach is that it is specific to a large, regional PBRN in the southeastern US. However, this approach could be tailored to other settings; we presented all the com- ponents of the process in this manuscript so others could choose elements of the approach that would be applicable to their setting.

In conclusion, we have presented a practical and replicable approach to building an engagement infrastructure for a PBRN using our network as an example. The main valuable lesson SERCN has gleaned from this process is that although it is time consuming, building this foundational infrastructure to engage with stakeholders has allowed us to nimbly convene consensus around projects and proposals, aligned efforts around shared mission across stakeholder groups in the network, and has built productive research partnerships. Engaging stakeholder communities into PBRN infrastructure has been a tenet that has guided the spirit of practice-based research since its inception and supports the conduct of research that is meaningful to stakeholder communities, can improve participation, and may facilitate meaningful exchange of wisdom between practice and evidence.

The authors thank Ms. Yasmeen Long for her guidance and support throughout this engagement process.

To see this article online, please go to: bttp://jabfm.org/content/ 32/5/695.full.

\section{References}

1. U.S. Department of Health and Human Services. Primary care practice-based research networks. October 2018. Available from: http://www.ahrq.gov/ research/findings/factsheets/primary/pbrn/index. html.

2. Kwan BM, Sills MR, Graham D, et al. Stakeholder engagement in a patient-reported outcomes (PRO) measure implementation: a report from the SAFTINet Practice-based Research Network (PBRN). J Am Board Fam Med 2016;29:102-15.

3. Elwyn G, Crowe S, Fenton M, et al. Identifying and prioritizing uncertainties: patient and clinician engagement in the identification of research questions. J Eval Clin Pract 2010;16:627-31.

4. Dolor RJ, Campbell-Voytal K, Daly J, et al. Practice-based research network research good practices (PRGPs): summary of recommendations. Clin Transl Sci 2015;8:638-46.

5. Green LA, White LL, Barry HC, Nease DE Jr, Hudson BL. Infrastructure requirements for practice-based research networks. Annals Fam Med 2005;3(Suppl 1):S5-S11.

6. Davis MM, Keller S, DeVoe JE, Cohen DJ. Characteristics and lessons learned from practice-based research networks (PBRNs) in the United States. J Healthc Leadersh 2012;4:107-16. 
7. Deverka PA, Lavallee DC, Desai PJ, et al. Stakeholder participation in comparative effectiveness research: defining a framework for effective engagement. J Comp Eff Res 2012;1:181-94.

8. Concannon TW, Meissner P, Grunbaum JA, et al. A new taxonomy for stakeholder engagement in patient-centered outcomes research. J Gen Intern Med 2012;27:985-91.

9. Forsythe L, Heckert A, Margolis MK, Schrandt S, Frank L. Methods and impact of engagement in research, from theory to practice and back again: early findings from the Patient-Centered Outcomes Research Institute. Qual Life Res 2018;27:17-31.

10. Christopher S, Watts V, McCormick AK, Young S. Building and maintaining trust in a communitybased participatory research partnership. Am J Public Health 2008;98:1398-406.
11. Israel BA. Methods for community-based participatory research for health. 2nd ed. San Francisco, CA: Jossey-Bass; 2012.

12. Nutting PA. Community-oriented primary care: from principle to practice. Albuquerque, NM: University of New Mexico Press; 1987.

13. Borkan J. Crystallization-immersion. Doing qualitative research. Washington, DC: Sage Publications. 1999;179-94.

14. Hickner J, Green LA. Practice-based research networks (PBRNs) in the United States: growing and still going after all these years. J Am Board Fam Med 2015;28:541-5.

15. Nutting PA, Beasley JW, Werner JJ. Practice-based research networks answer primary care questions. JAMA 1999;281:686-8. 


\section{Southeast Regional Clinicians Network Stakeholder Meeting \\ Morehouse School of Medicine, Atlanta, GA \\ Monday, February 19}

7:30 am

8:00 am

$8: 30 \mathrm{am}$

9:20 am

9:30 am

\section{BREAKFAST \& CHECK-IN}

Welcome \& Overview of the Day - Dr. Anne Gaglioti \& Denita Walston

Welcome and Overview of Agenda

Introductions

SERCN Status Report and Research Update

Practice-Based Research in FQHCs (40 mins, Q\&A 10 mins)

George Rust, MD, MPH, Director, Center for Medicine and Public Health

Florida State University College of Medicine

\section{BREAK}

Stakeholder Workshop: Setting a Research Agenda

9:30-10:00 am Overview of Results from Network Wide Engagement Effort Dr. Anne Gaglioti

10:00-10:45 Workshop: Translating Results to Define a SERCN Research Agenda and Guiding Principles

Facilitators: Anne Gaglioti and Denita Walston

10:45-11:00 am Break

11:00-11:30 am Finalize Research Priorities and Guiding Principles

11:30-11:45 am Identify Executive Committee Candidates (5 positions)

11:45 am BREAK

12:00 pm LUNCH - UDS/PBRN connections and opportunities with ACS

(40 mins, Q\&A 10 mins)

Laura Makaroff, DO | Senior Director, Cancer Control Intervention

American Cancer Society, Inc.

1:00 pm Distribute Executive Committee Ballots and Vote for Candidates

1:15 pm Discussion Breakout Sessions (60 mins)

Two Small Groups will discuss the following Topics (20 minutes each)

\begin{tabular}{|l|l|l|}
\hline Identifying Key Barriers and & Identifying Strategies to Implement \\
Facilitators to implementing PCOR & PCOR in SERCN \\
Agenda in SERCN & & $\begin{array}{l}\text { Identifying Preferred Methods of } \\
\text { Engagement around PCOR and } \\
\text { Training Opportunities }\end{array}$ \\
\hline
\end{tabular}

2:15-3:15 pm Discussion Recap (40 - 60 mins)

3:15 pm Break

3:30 pm Concluding Remarks

Announcement of Executive Committee

Core Activities to Move SERCN Forward Over the Next Five Years

4:00 pm WRAP-UP / DEPARTURE 